Canadian

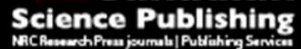

Canadian Journal of Physiology and Pharmacology Revue canadienne de physiologie et pharmacologie

\title{
Pathophysiology and Prevention of Sudden Cardiac Death
}

\begin{tabular}{|r|l|}
\hline Journal: & Canadian Journal of Physiology and Pharmacology \\
\hline Manuscript ID & cjpp-2015-0366 \\
\hline Manuscript Type: & Review \\
\hline Date Submitted by the Author: & 10 -Aug-2015 \\
\hline Complete List of Authors: & $\begin{array}{l}\text { Goyal, Vineet; Institute of Cardiovascular Sciences } \\
\text { Jassal, Davinder; St. Boniface General Hospital, University of Manitoba, } \\
\text { Institute of Cardiovascular Sciences } \\
\text { Dhalla, Naranjan; Institute of Cardiovascular Sciences }\end{array}$ \\
\hline Keyword: & $\begin{array}{l}\text { sudden cardiac death, arrhythmias, dilated cardiomyopathy, hypertrophic } \\
\text { cardiomyopathy, coronary artery disease }\end{array}$ \\
\hline
\end{tabular}

SCHOLARONE ${ }^{m}$

Manuscripts 


\title{
Pathophysiology and Prevention of Sudden Cardiac Death
}

\author{
Vineet Goyal, ${ }^{1}$ Davinder S. Jassal, ${ }^{1,2}$ Naranjan S. Dhalla ${ }^{1}$
}

1) Institute of Cardiovascular Sciences, St. Boniface Hospital Research Centre, Department of Physiology and Pathophysiology, College of Medicine, Faculty of Health Sciences, University of Manitoba, Winnipeg, Manitoba, Canada.

2) Section of Cardiology, Department of Internal Medicine, College of Medicine, Faculty of Health Sciences, University of Manitoba, Winnipeg, Manitoba, Canada.

\section{Address for Correspondence}

Dr. Naranjan S. Dhalla

Institute of Cardiovascular Sciences

St. Boniface Hospital Research Center

351 Tache Avenue

Winnipeg, MB, R2H 2A6, Canada

Telephone: 204-235-3417

Email:nsdhalla@sbrc.ca 


\begin{abstract}
Sudden cardiac death (SCD) is known to occur in individuals with diverse diseases. Each disease state has a specific etiology and pathophysiology, and is diagnosed and treated differently. Etiologies for SCD include cardiac arrhythmias, coronary artery disease, congenital coronary artery anomalies, hypertrophic cardiomyopathy, arrhythmogenic right ventricular dysplasia, dilated cardiomyopathy, and aortic valve stenosis. A potential unifying mechanism of SCD in these diseases involves a massive stimulation of the sympathetic nervous system's stress response and the subsequent elevation of circulating catecholamines. The diagnosis of cardiac diseases that contribute to an increased risk for SCD is accomplished by a combination of different techniques including electrocardiography, echocardiography, magnetic resonance imaging, and invasive cardiac catheterization. Several therapies including antiarrhythmic drugs, $\beta$ blockers, and antiplatelet agents may be used as medical treatment in patients for the prevention of SCD. Invasive therapies including percutaneous angioplasty, coronary artery bypass surgery, and implantable cardioverter-defibrillators are also used in the clinical management of SCD.
\end{abstract}

Keywords: Sudden Cardiac Death, Arrhythmias, Dilated Cardiomyopathy, Hypertrophic Cardiomyopathy, Coronary Artery Disease 


\section{Introduction}

Sudden cardiac death (SCD), commonly referred to as sudden cardiac arrest, is defined as the unexpected loss of heart function, breathing, and consciousness (Ferreira et al. 2010). Sudden cardiac death most commonly occurs through an electrical disturbance that affects cardiac systolic function, leading to inadequate delivery of blood to the rest of the body. SCD is further characterized as death due to cardiac cause that occurs within one hour of onset of arrhythmias (Friedewald and Spence 1990). The symptoms of SCD including syncope, loss of breathing, loss of pulse, and sudden collapse are all rapid and dramatic. The early symptoms include fatigue, syncope, weakness, palpitations, and vomiting (Berger and Campbell 2009). A major problem with these symptoms is the lack of specificity for a cardiac event. Additionally, there are no well-defined criteria for the predictability for SCD, making it difficult to risk stratify this patient population. As one in every three deaths in the United States is of cardiac cause and about $50 \%$ of these result in SCD, it is concluded that SCD is the leading cause of death in the country (Kong et al. 2011). In this article, we have attempted to review the existing literature on the etiologies and pathophysiology of different diseases which predispose individuals to SCD. In addition to describing several mechanisms of SCD, the focus of this review article is to discuss different medical therapies and interventions for the prevention of this major health issue.

\section{A. Etiologies and Pathophysiology of SCD}

An increased risk for SCD is characterized by a multitude of etiologies encompassing many pathological manifestations. These etiologies for SCD include cardiac arrhythmias, coronary artery disease, congenital coronary artery anomalies, 
hypertrophic cardiomyopathy, arrhythmogenic right ventricular dysplasia, dilated cardiomyopathy, and aortic valve stenosis (Figure 1). The following discussion is concerned with the pathophysiology of different disease states thereby formulating a potential unifying mechanism for SCD.

\section{Cardiac Arrhythmias}

SCD is most often caused by cardiac arrhythmias, which alter the electrical conductivity of the heart (Thiene 2014). The specialized electrical conductivity cells localized in the upper right atrium, known as the sinus node, are commonly involved in the appearance of these cardiac arrhythmias (Aro and Huikuri 2013). The arrhythmia most often associated with SCD is ventricular fibrillation (VF); causing rapid and desynchronized ventricular flutter resulting in reduced left ventricular ejection fraction (Francis and Namboodiri 2014). The onset of this ventricular arrhythmia is often associated with other cardiac pathologies which may act as a trigger to induce the ventricular fibrillation observed in SCD.

Another predisposing electrical manifestation of SCD is the prolonged QT syndrome. Long QT syndrome (LQTS) affects the rhythmic action of the heart. Each heartbeat is normally followed by an electrical recharge period, which prepares it for the next beat, thus adequately pumping blood to the periphery (Ackerman 2008). This process is known as a repolarization period, and is irregularly longer than normal in patients suffering from LQTS. On a resting EKG, the distance between the $\mathrm{Q}$ and $\mathrm{T}$ wave is representative of the time it takes for the heart to contract and then refill with blood before beginning the next contraction (Thorsen et al. 2006). A prolonged QT $>500 \mathrm{msec}$ can cause ventricular fibrillation leading to compromised heart function. This change in 
rhythm can cause syncope, seizures, and SCD due to inadequate ejection of blood form the heart (Vincent 2005).

Recent studies have investigated the cause of LQTS, and have concluded that congenital ion channel defects play a major role in causing this arrhythmia (Postema and Wilde 2008). It has been reported that these channelopathies are correlated to an increased risk of SCD. The mutation is most observed in the cardiac ion channel genes $K C N Q 1, K C N H 1$, and $S C N 5 a$, which are detected in every one out of 2000 people (Postema and Wilde 2008). However, the majority of carriers of this genetic defect do not present with phenotypic changes with respect to their QT interval (Roden 2008). In contrast to inherited LQTS, many patients also suffer from acquired long QT syndrome, a disease that is most often associated with drug-induced arrhythmias. This usually occurs through the use of medications that block the cardiac potassium channel known as hERG (Saenen and Vrints 2008). There are currently approximately 50 known medications ranging from lipid lowering agents and anti-depressants, to anti-arrhythmic drugs, that are considered to cause acquired LQTS (Lee et al. 2008).

\section{Coronary Artery Disease}

One of the most common triggers for SCD is coronary artery disease (Dhalla et al.; Thiene 2014). CAD associated with SCD is often caused by a single vessel disease with the atherosclerotic plaque located in the proximal left anterior descending coronary artery, an area known as the "SCD arterial segment" (Thiene 2014). In 30\% of cases of $\mathrm{CAD}, \mathrm{VF}$ develops as the disease progresses, leading to eventual SCD due to the occlusion of the arteries. These patients often suffer from CAD caused by endothelial dysfunction, or fibrous cap rupture (Thiene 2014). In contrast to this, the other $70 \%$ of 
patients often suffer from coronary vasospasms, which cause an obstruction leading to ST-segment elevation (Krexi et al. 2015; Thiene 2014). The onset of VF is seen during reperfusion, rendering the patient at significant risk for SCD. Patients that have already suffered a ST elevation myocardial infarction are left with areas of scar tissue which act as reservoirs for electrical short circuits causing abnormal heart rhythms, thereby placing them at an even further risk for SCD (Buxton et al. 2003; Krexi et al. 2015; Sara et al. 2014).

In contrast to acquired $\mathrm{CAD}$, certain patients may be predisposed to SCD from birth due to congenital coronary artery anomalies (CCAA) (Sara et al. 2014). Normal coronary anatomy is characterized by two ostia, which are centrally placed between the left and right sinus of the Valsalva. The left main coronary artery originates from the left ostium and branches into the left anterior descending artery and circumflex artery, eventually penetrating the myocardium in a highly divided fashion. The right coronary artery arises from the right ostium, providing an infundibular branch to the anterior side of the heart (Hauser 2005). The most common lethal variant of CCAA includes wrongful sinus coronary artery origin, in which the left main artery is arising from the right anterior sinus or the right coronary artery arising from the left sinus, with proximal course between the aorta and the pulmonary trunk (Davis et al. 2001). The prevalence of CCAA in the general population still remains uncertain; however, previous studies have shown $0.2 \%$ to $1 \%$ of patients undergoing catheterization had an occurrence of CCAA, suggesting that the prevalence of the disease is quite low in the general population (Yamanaka and Hobbs 1990). These findings require further investigation, due to the fact that many patients with CCAA are asymptomatic, and there are no routine screening 
procedures for this problem. It has been reported that $30 \%$ of patients that suffer from CCAA are symptomatic with chest discomfort, atypical chest pain, and/or syncope. These symptoms are usually exaggerated with physical activity and cardiovascular stress (Davis et al. 2001; Yamanaka and Hobbs 1990). The complex nature of SCD is highlighted through changes in the electrophysiology of the heart, as well as variations in the coronary arteries.

\section{Hypertrophic Cardiomyopathy}

Different types of cardiomyopathies are known to represent a common risk for the development of SCD. A particular disease state known as hypertrophic cardiomyopathy (HCM) is defined as an abnormal thickening of the muscular walls of the heart, which often results in SCD (Richardson et al. 1996). HCM exerts its detrimental effects on cardiac health by directly altering the functionality of the contractile cardiac cells (Maron 2002a). These cardiomyocytes grow abnormally in size and result in the chamber thickening associated with SCD. The large cardiomyocytes lead to a misalignment of cells in a phenomenon known as myocardial disarray and ultimately become nonfunctional (Maron 2002a,b,c). The implications of these structural changes in the myocardium are multifaceted and may be catastrophic. Patients with HCM may suffer from dyspnea due to decreased ventricular filling, angina due to restricted or reduced blood flow of the coronary arteries, palpations due to ischemia from reduced coronary flow, and altered electrophysiological characteristics of the heart due to the cardiomyocyte disarray (Bonow 2015; Gersh et al. 2011). It is clear that HCM has global effects on the entire physiology of the heart, thus making it a complex disease to understand and treat. 
The cause of HCM has been classified as an autosomal dominant disorder which affects the genes that code for sarcomere proteins (Bonow 2015). A recent study has shown that this genetic anomaly affects approximately 1 in every 500 people, causing SCD in patients of all ages (Lopes et al. 2013). Mutations that affect the Z-disc or calcium handling proteins account for about $1 \%$ of this disease population, suggesting that most patients are directly affected through altered sarcomere protein expression (Lopes et al. 2013; Marian et al. 2001; Morita et al. 2008). The leading gene involved in the development of HCM is the cardiac myosin binding protein $\mathrm{C}$ (MYCPC3) (Bonow 2015). It has been reported that this gene mutation is highly variable and accounts for $80 \%$ of the total myosin binding protein present in humans. Thus, the genetic inheritance of this disease is known to be exceedingly variable with respect to its phenotypic presentation. In addition, there is a lack of correlation between the genotypic composition of mutations and the phenotypic presentation of SCD (Bonow 2015). In order to further characterize the genes involved in SCD, recent studies using high throughput sequencing have attempted to identify key mutations in the cardiovascular gene pool, and their role in the development of the HCM (Lopes et al. 2013). These investigations conducted the first large-scale study, which identified the sarcomere gene variants in patients with HCM, concluding that there are numerous non-synonymous rare variants with unknown clinical significance (Lopes et al. 2013).

\section{Arrhythmogenic Right Ventricular Dysplasia}

Another heritable cardiomyopathy that can lead to SCD is arrhythmogenic right bentricular dysplasia, commonly known as ARVD. This disease is known to cause arrhythmias and heart failure, ultimately leading to SCD (Wolfe and Corwin 2005). The 
most common manifestations of the disease include right ventricular enlargement, fibrofatty replacement of myocytes in the right ventricle (RV), and ventricular arrhythmias (Murray 2012). Approximately 20\% of people who suffer from SCD have ARVD, thus clearly showing the severity of this disease and its ability to cause mortality (Tabib et al. 2003). The clinical significance of ARVD is further indicated by the fact that SCD is the first presenting symptom in approximately 50\% of cases (Murray 2012). Recent real world studies have revealed that the occurrence of this disease is as high as 1 in 1000, a number that is often underestimated (Murray 2012).

The pathology of ARVD involves abnormalities in the genes encoding for desmosomes (Shimizu and Shimomura 1991). Desmosomes are complex protein structures that offer structural and functional support properties to adjacent cardiomyocytes and epithelial cells (Tandri et al. 2008; Wolfe and Corwin 2005). More specifically, desmosomes are cell-cell junctions that mediate adhesion and allow the microfilaments of the cytoskeleton to associate with sites of cell to cell contact (Stahley and Kowalczyk 2015). One of the proteins of the desmosome complex involved in the pathology of ARVD is desmoplakin, the lack of which is associated with the intercalated discs of the myocardium of mice. This observation led to further investigations into the correlation between ARVD and the desmosome proteins (Bierkamp et al. 1996). Several studies have shown that abnormal desmosomes cause a loss of myocyte adhesion leading to cell death, regional fibrosis, and eventually the characteristic arrhythmias associated with ARVD (Awad et al. 2008; Bouska et al. 2008; Coumbe et al. 1997). In addition to the structural implications of desmosomes, they are also intimately involved in 
intracellular signal transduction pathways, which are essential to normal cardiomyocyte function (Garcia-Gras et al. 2006).

The specific mechanisms of desmosome dysfunction that lead to the clinical manifestations of ARVD have been recently hypothesized. The first hypothesis involves the degeneration of cardiomyocytes due to abnormal desmosomes, which leads to the fibrofatty replacement of the normal myocardium. This theory is supported by the clinical progression of ARVD and its associated loss of myocardium (Angelini et al. 1996; Basso et al. 1996; Menghetti et al. 1996). The second hypothesis outlines the implications of signal transduction pathway interference. The changes in these pathways mainly alter the electrical conductivity of the heart, leading to a slower conduction, loss of cardiomyocytes, and induction of fibrosis and adipogenesis. The underlying cause of these outcomes is attributed to the idea that a disruption in desmosomes leaves the cardiomyocytes unable to overcome mechanical stress, leading to myocyte apoptosis ( $\mathrm{Li}$ et al. 2011a,b). The third proposed theory for the development of ARVD explores the effects of inflammation on the heart. In this regard, myocarditis has been linked to cardiomyocyte necrosis, and is seen in the pathological examination of hearts from ARVD patients (Murray 2012). It is postulated that these pro-inflammatory cells are abundant during ARVD progression, and may be involved in provoking cardiac arrhythmias (Bauce et al. 2005).

\section{Dilated Cardiomyopathy}

Another disease of the myocardium that is associated with SCD is dilated cardiomyopathy (DCM). This disease is defined as an ailment of the heart muscle, 
usually originating in the left ventricle, and is characterized as a dilation of the left or right ventricles of the heart, leading to a decrease in systolic ventricular function (Kasper et al. 1994). This decrease in function leads to a progressive reduction in the patient's left ventricular ejection fraction, leading to inadequate tissue perfusion. This frequently results in cardiac remodeling in which the ventricles undergo hypertrophy, which could lead to congestive heart failure (Luk et al. 2009). Often, patients with DCM suffer from symptoms including syncope, shortness of breath, and angina in the setting of ischemic heart disease (Kasper et al. 1994). Other symptoms that may develop during progressive DCM include pulmonary edema, elevated jugular venous pressure, and low pulse pressure (Oldfors et al. 1994).

The exact cause of DCM remains unknown in many cases, but is often associated with a damaged myocardium in a variety of situations. Toxins and infectious agents are known to cause acute myocarditis, which can directly cause DCM in many patients (Martino et al. 1994). A virus of interest that is involved in the development of DCM is coxsackievirus B (CVB). Different studies have explored the relation of CVB to the development of DCM, and have concluded that there is circumstantial evidence but no definitive proof for a viral etiology in DCM (Martino et al. 1994). More recent investigations into the pathogenic cause of DCM have linked the parovirus B19 with a significant number of patients suffering from the disease (Kuhl et al. 2005). Given this, it is evident that a subset of viral genomes can be identified in certain patients with DCM; however, the impact of these viruses on cardiac function and clinical outcomes remains controversial (Yajima and Knowlton 2009). 
In contrast to viral causes of DCM, it has been shown that hereditary forms of DCM are present in about $25 \%$ of patients (Ross 2002). One of the most impactful mutations causing DCM involves the intermediate filament protein desmin (Goldfarb et al. 1998). Desmin is defined as a muscle specific intermediate filament protein associated with the sarcolemma, Z-disk, and nuclear membrane in the contractile cells of the heart (Sequeira et al. 2014). Furthermore, alterations in the muscle LIM protein have been reported in patients with heart failure from DCM. This protein is also involved in cytoskeleton stability and associates with the Z-disk in order to ensure proper contractility of cardiomyocytes (Zolk et al. 2000). Dystrophin is another protein associated with DCM, which functions to provide stability and cell signaling. The muscular dystrophy caused by Duchenne's disease is known to affect dystrophin, potentially causing DCM, leading to SCD (Ross 2002). Genes that cause DCM are often those that provide structural support, signaling between cellular components, and cytoskeletal stability for cells (Ross 2002).

\section{Valvular Heart Disease}

SCD can also be caused by valvular disorders including aortic stenosis (AS), which is defined as a hemodynamically significant narrowing of the outlet of the left ventricle thereby impeding the normal outflow (Czarny and Resar 2014). The cause of AS may be due to congenital defects in the trileaflet formation of the aortic valve, or rheumatic fever, which predisposes the valve to calcification and stenosis. The progression of AS may continue over decades, beginning with inflammation, and continuing to fibrosis, valve thickening, and calcification. As the valve becomes progressively calcified, the leaflets lose mobility and the valve becomes increasingly 
stenotic (Czarny and Resar 2014). The symptoms that follow include angina, palpitations, heart murmurs, syncope, and dyspnea. If the AS is left untreated it can progress and cause SCD (Ruiz Ruiz et al. 2003). Syncope and SCD in patients with AS is a result of a diminished coronary arterial blood flow as a result of acute LV failure, and decreased cardiac output (Kulbertus 1988).

\section{B. Pathophysiological Mechanisms of SCD}

A potential unifying mechanism for SCD that encompasses many of the disease etiologies includes the marked activation of the sympathetic nervous system and the massive release of catecholamines during the stress response. One of the downstream effects of prolonged elevation of catecholamines includes the activation of $\alpha$ - and $\beta$ adrenoreceptors (Adameova et al. 2009). The activation of the $\beta$-adrenoreceptors is proposed to have a pivotal role in the development of SCD (Steinfath et al. 1992). The activation of $\beta$-adrenoreceptor coupled $\mathrm{G}_{\mathrm{s}}$ proteins by catecholamines leads to the activation of adenylyl cyclase, which catalyzes the formation of cyclic AMP from ATP. The formation of cyclic AMP goes on to activate protein kinase A, which subsequently induces the phosphorylation of voltage dependent L-type calcium channels (Adameova et al. 2009). This phosphorylation of L-type calcium channels leads to a significantly increased influx of $\mathrm{Ca}^{2+}$ into myocardial cells during the cardiac action potential, which further triggers the release of $\mathrm{Ca}^{2+}$ from the sarcoplasmic reticulum via the ryanodine receptors (Castellano and Bohm 1997). This alteration in calcium handling is known to induce ventricular arrhythmias that are commonly associated with SCD (Adameova et al. 2009). 
In addition to the detrimental cascade involving the $\beta$-adrenoreceptors, it is postulated that $\alpha$-adrenoreceptors may play a role vascular remodeling, proliferation, and hypertrophy during the stress response.(Zhang et al. 2002) The stimulation of aadrenoceptors by increased levels of catecholamines also leads to detrimental effects in the coronary arteries (Dhalla et al. 2010). Prolonged exposure to high levels of circulating catecholamines results in coronary spasm causing myocardial ischemia, which may contribute to etiologies involved in SCD (Dhalla et al. 2010). The ischemia associated with coronary spasms can also cause decreased aortic pressure and dilatation of the arteriovenous shunts, leading to a multidimensional hypoxia (Rona et al. 1973).

The detrimental effect of elevated levels of catecholamines, and their role in the pathogenesis of SCD, is further potentiated when these molecules are subject to autooxidation. The oxidized products of catecholamines lead to the generation of aminochromes, which have been proven to be detrimental to cardiomyocytes (Behonick et al. 2001). The formation of these oxidized end products is directly correlated to an increase in superoxide anions and subsequent hydrogen peroxide, which is known to cause DNA degradation, protein denaturation, and lipid damage, thus increasing the risk of SCD at a molecular level (Dhalla et al. 2000). During this stress response, it has also been reported that the incidence of platelet aggregation and atherosclerotic plaque formation is augmented, thereby increasing the risk of CAD (Brydon et al. 2006). It has been shown that elevated circulating catecholamine levels increase platelet aggregation, which results in an increased risk of coronary artery occlusion leading to myocardial infarction (Haft et al. 1972). These findings have given rise to the unifying theory for 
stress induced SCD, which encompasses multiple etiologies under one molecular phenomenon.

It should be noted that an increase in oxidative stress is often associated with damage to the endothelium of the vasculature (Heitzer et al. 2001). The endothelium is known to be intimately involved in regulation of vascular tone, platelet activity, leukocyte adhesion, and thrombosis (Heitzer et al. 2001). Damage to this inner lining of the vasculature can cause severe consequences through multiple etiologies. Specifically, a prolonged stress response can result in the excessive release of endothelin-1 from the endothelium, which may be attributed to an increased risk for SCD (Lerman and Zeiher 2005). Endothelin-1 is normally responsible for vasoconstriction and is seen to be in an intricate balance with vasodilators such as nitrous oxide (NO) (Lerman and Zeiher 2005). When this balance is offset by an excess of endothelin-1, patients often suffer from vasospasm leading to tissue ischemia and eventual necrosis (Spieker et al. 2002). To further compound this imbalance, the damaging effects of oxidative stress on the endothelium leave this system with an impaired ability to release NO (Spieker et al. 2002). This disturbance may be directly linked to an increased risk of SCD through the development of CAD.

\section{Diagnosis and Screening of Patients at Risk of SCD}

The resting EKG is useful when it comes to diagnosing and screening patients for an increased risk of SCD. Since many of the diseases involve a disturbance in the electrical conductance of the heart, this diagnostic tool can provide tremendous insight into the pathology of the disease and its progression. It has been reported that $95 \%$ of patients that have a high risk of SCD demonstrate abnormal ECG tracings (Montgomery 
et al. 2005). The findings from the ECG tracings are often non-specific for SCD, and require further supporting evidence to accurately diagnose risk for this disease (Gow 2009). ECG testing can provide insight into the etiology which is potentially placing the patient at risk for SCD. ARVD is classically characterized by inverted T-waves in the mid-precordial leads, widened or fragmented QRS complexes, and abnormal complexes on the S wave on the right chest leads (Gow 2009). Patients who are diagnosed with ARVD are often further assessed for comorbidities and the potential risk for SCD. In contrast to ARVD, congenital coronary artery disease does not normally present with any specific findings on ECG (Basso et al. 1996). In addition, any cardiac arrhythmias, that are secondary to the alone mentioned etiologies, can offer insight into the potential risk for SCD, but often require further testing to have clinical significance (Franco et al. 2014).

Another important non-invasive imaging technique for the detection of risk for SCD in patients is echocardiography. The utility of echocardiography in the setting of SCD can be especially useful in detecting valvular abnormalities, aortic root dilatation, left ventricular dysfunction, and assessment of the left ventricular ejection fraction (Maron 1997). The use of this imaging technique is ideal for certain conditions that are associated with diseases including $\mathrm{HCM}$ or DCM, but cannot be used to accurately diagnose conditions such as congenital coronary anomalies. In certain cases, echocardiography can be used to raise a clinical suspicion of wrongful coronary artery origin, but there is often need for further screening to make an accurate diagnosis (Gaither et al. 1991; Maron et al. 1991). In contrast, patients that are at risk for SCD as a 
result of HCM can be accurately assessed by echocardiography (Spirito and Maron 1990; Spirito et al. 1985).

The parameters obtained from echocardiography are known to have a low sensitivity in predicting risk for SCD (Aljaroudi et al. 2013). It was shown that the presence of scar and myocardial tissue heterogeneity are directly linked to provoking cardiac arrhythmias, which are a direct cause of SCD (Aljaroudi et al. 2013; Wagner et al. 2003). Cardiac magnetic resonance imaging (CMR) is another non-invasive imaging technique that quantifies scars and has recently been seen to add predictive value for patients at risk for SCD (Aljaroudi et al. 2013). CMR is able to visualize myocardial scar through the use of late gadolinium enhancement (LGE), which has proven histopathological correlation (Moon et al. 2004). This technique offers a high spatial resolution, which allows for the differentiation of varying scar patterns, and allows for detection of interstitial fibrosis, and edema (Flett et al. 2010; Iles et al. 2008). In addition, the geographic distribution of LGE allows for the technique to distinguish between different cardiomyopathies, which is very useful for the risk stratification of patients for SCD (Aljaroudi et al. 2013).

Finally, the use of invasive diagnostic techniques such as cardiac catheterization is important in diagnosing etiologies involving the coronary arteries for SCD. The main findings from cardiac catheterization include the evaluation or presence of coronary artery disease, valvular disease, and/or aortic disease (Iskandrian et al. 1978). This invasive procedure can also evaluate the presence of anomalous congenital coronary arteries that may be placing patients at risk for SCD (Lange and Hillis 2003). This 
procedure is most often implemented when there is a clinical suspicion of CAD from other non-invasive diagnostic screening tools (Lange and Hillis 2003).

\section{Medical Therapy and Interventions}

Treatment for patients at risk for SCD includes medical therapy with pharmaceuticals as well as invasive intervention. The wide range of therapies for SCD is rooted in the nature of disease, which includes a multitude of etiologies. Treatment for patients at risk for SCD includes the use of $\beta$-adrenoreceptor blockers, antiplatelet agents, and antiarrhythmic drugs (Figure 2). In addition, patients at increased risk for SCD may also seek intervention, including revascularization via percutaneous coronary intervention or coronary artery bypass surgery. Finally, patients may also benefit from the insertion of an implantable cardioverter-defibrillator (ICD) for either primary or secondary prevention of SCD (Figure 2). It should be emphasized that all these drugs and interventions in different diseases are used to delay or prevent the occurrence of SCD.

Management for patients at risk for SCD includes the use of medical treatment by pharmaceuticals. $\beta$-adrenoreceptor blockers in particular, have been extensively studied for their efficacy in the setting of heart failure leading to SCD. This class of drug has been approved as a cardiovascular medication for reducing morbidity and mortality in patients with heart failure (DiNicolantonio et al. 2015). The use of $\beta$-adrenoreceptor blockers is important in preventing cardiac arrhythmias, and myocardial infarction, two etiologies that are often the cause of SCD (Freemantle et al. 1999). These drugs work by attenuating the action of endogenous catecholamines, specifically the $\beta$-adrenergic receptors, which alter the sympathetic response in the heart (Cruickshank 2010). The two most highly prescribed beta-blockers in the heart failure setting are metoprolol and 
atenolol, both of which have been seen to improve patient outcomes (Go et al. 2008; Stork et al. 2008). Metoprolol is a selective $\beta-1$ receptor blockade medication, which is specific to the receptor in cardiac tissue (Go et al. 2008). Similarly, atenolol is also a selective $\beta-1$ antagonist which binds the specific beta receptor found in cardiac tissue, but does not elicit the response that is normally accompanied by this binding, thereby protecting the heart from the stress response (Go et al. 2008).

Another pharmaceutical agent that has shown promise in reducing the occurrence of SCD is aspirin, which is also known to exert antiplatelet actions. This drug offers a multitude of cardiac health benefits to patients who may prophylactically start aspirin therapy based on their risk of SCD (Rollins 2002). Aspirin is able to decrease inflammation, which is an important part of the pathology of plaque formation that causes myocardial infarction and stroke (Rollins 2002). Aspirin is able to block cyclooxygenase which in turn reduces the amount of inflammatory prostaglandins. The inhibition of these prostaglandins also plays a role in reducing the formation of blood clots, thereby decreasing the risk of coronary artery complications (Rollins 2001). The efficacy of aspirin as a prophylactic treatment to reduce the incidence of SCD is further strengthened when it is a part of a combined therapy, usually conjunct with clopidogrel (Zhou et al. 2012). Clopidogrel is an antiplatelet agent which is known to decrease the incidence of clot formation in those who suffer from coronary artery disease. The combined use of these agents has been reported to have a $1.1 \%$ overall risk reduction in a major cardiovascular event, but a major drawback is the risk of major bleeding events (Zhou et al. 2012). 
A more invasive approach to treating patients at risk for SCD includes the use of percutaneous angioplasty, as well as other coronary interventions. Coronary bypass surgery is often used as an intervention for patients suffering form CAD. This surgery involves diverting blood flow around a section of a blocked artery in order to reduce the ischemia associated with CAD (Hammermeister et al. 1977). These investigations evaluated the difference in patient outcomes between medical therapy and coronary bypass intervention for patients with CAD. The two experimental groups were very similar in their degree of CAD and left ventricular ejection fractions. The outcome of the study showed that patients with similar baseline characteristics did benefit from intervention as compared to medical therapy, with respect to improved survival (Hammermeister et al. 1977).

Recent efforts to improve survival of patients with CAD have led to the development of drug eluting stents (DES). DES are scaffolds which are placed into narrowed, and diseased coronary arteries that elute drugs that decrease cell proliferation in the already narrowed vessel (Hannan et al. 2008). DES were introduced in 2003 for the purpose of reducing restenosis in patients with bare-metal stents. These revolutionary stents have been seen to decrease angiographic restenosis, target lesion revascularization, and major adverse cardiac events in a multitude of randomized control trials (Ardissino et al. 2004; Morice et al. 2002; Moses et al. 2003). It has been reported that DES do not offer benefit to patient outcomes as compared to coronary artery bypass in multivessel coronary artery disease (Hannan et al. 2008). This study concluded that coronary artery bypass is associated with lower mortality rates as compared to intervention with DES. 
These findings allow clinicians to implement the best intervention to patients who may be at risk for SCD due to varying degrees of CAD.

Finally, implantable cardioverter-defibrillators (ICD) offer the ability to cardiovert, defibrillate, and pace the heart. ICDs are often used as prophylactic treatment for SCD caused by ventricular tachycardia and fibrillation (Mirowski et al. 1980). There have been investigations into the use of antiarrhythmic drugs versus ICDs in the prevention of life threatening arrhythmias. Different studies have shown that the use of antiarrhythmic drugs, such as amiodarone, for the prevention of SCD remains controversial (Doval et al. 1994; Singh et al. 1995). Given this, subsequent studies have evaluated the use of ICD's in the heart failure setting. It has been reported that simple shock ICD therapy improves survival much more than state of the art pharmaceutical therapy for mild to moderate congestive heart failure (Bardy et al. 2005).

Given all of the advancements that have been made in treatment and intervention for risk reduction of $\mathrm{SCD}$, further research is required to create a concrete set of guidelines for patients with specific diseases. This is often problematic seeing as many patients suffer from comorbidities and have multiple myopathies that further complicate diagnosis and treatment protocols. By further characterizing the various diseases that place patients at increased risk for SCD, clinicians will be able to make the best recommendations for improved patient survival. The growing body of research into the various etiologies is helping shape the diagnostic and treatment guidelines for this complex disease. 


\section{.Acknowledgements}

The St. Boniface Hospital Research Foundation provided infrastructural support for this project. 


\section{References}

Ackerman, M.J. 2008. Unmasking concealed long QT syndrome. Heart Rhythm, 5(1): 8-10. doi: 10.1016/j.hrthm.2007.11.009.

Adameova, A., Abdellatif, Y., and Dhalla, N.S. 2009. Role of the excessive amounts of circulating catecholamines and glucocorticoids in stress-induced heart disease. Can. J. Physiol. Pharmacol. 87(7): 493-514. doi: 10.1139/y09-042.

Aljaroudi, W.A., Flamm, S.D., Saliba, W., Wilkoff, B.L., and Kwon, D. 2013. Role of CMR imaging in risk stratification for sudden cardiac death. J. Am. Coll. Cardiol. Cardiovasc. Imaging, 6(3): 392-406. doi: 10.1016/j.jcmg.2012.11.011.

Angelini, A., Basso, C., Nava, A., and Thiene, G. 1996. Endomyocardial biopsy in arrhythmogenic right ventricular cardiomyopathy. Am. Heart J. 132(1 Pt 1): 203-206.

Ardissino, D., Cavallini, C., Bramucci, E., Indolfi, C., Marzocchi, A., Manari, A., et al. SES-SMART Investigators. 2004. Sirolimus-eluting vs uncoated stents for prevention of restenosis in small coronary arteries: a randomized trial. J. Am. Med. Assoc. 292(22): 2727-2734. doi: 10.1001/jama.292.22.2727.

Aro, A.L., and Huikuri, H.V. 2013. Electrocardiographic predictors of sudden cardiac death from a large Finnish general population cohort. J Electrocardiol. 46(5): 434-438. doi: 10.1016/j.jelectrocard.2013.06.016.

Awad, M.M., Calkins, H., and Judge, D.P. 2008. Mechanisms of disease: molecular genetics of arrhythmogenic right ventricular dysplasia/cardiomyopathy. Nat. Clin. Pract. Cardiovasc. Med. 5(5): 258-267. doi: 10.1038/ncpcardio1182.

Bardy, G.H., Lee, K.L., Mark, D.B., Poole, J.E., Packer, D.L., Boineau, R., et al. Sudden 
Cardiac Death in Heart Failure Trial Investigators. 2005. Amiodarone or an implantable cardioverter-defibrillator for congestive heart failure. N. Engl. J. Med. 352(3): 225-237. doi: 10.1056/NEJMoa043399.

Basso, C., Thiene, G., Corrado, D., Angelini, A., Nava, A., and Valente, M. 1996. Arrhythmogenic right ventricular cardiomyopathy. Dysplasia, dystrophy, or myocarditis? Circulation, 94(5): 983-991.

Bauce, B., Basso, C., Rampazzo, A., Beffagna, G., Daliento, L., Frigo, G., et al. 2005. Clinical profile of four families with arrhythmogenic right ventricular cardiomyopathy caused by dominant desmoplakin mutations. Eur. Heart. J. 26(16): 1666-1675. doi: 10.1093/eurheartj/ehi341.

Behonick, G.S., Novak, M.J., Nealley, E.W., and Baskin, S.I. 2001. Toxicology update: the cardiotoxicity of the oxidative stress metabolites of catecholamines (aminochromes). J. Appl. Toxicol. 21 Suppl 1: S15-22.

Berger, S., and Campbell, R.M. 2009. Sudden cardiac death in children and adolescents: introduction and overview. Pacing Clin. Electrophysiol. 32 Suppl 2: S2-5. doi: 10.1111/j.1540-8159.2009.02378.x.

Bierkamp, C., McLaughlin, K.J., Schwarz, H., Huber, O., and Kemler, R. 1996. Embryonic heart and skin defects in mice lacking plakoglobin. Dev. Biol. 180(2): 780-785. doi: 10.1006/dbio.1996.0346.

Bonow, R.O. 2015. Hypertrophic cardiomyopathy: past, present... and future. Trends Cardiovasc. Med. 25(1): 65-66. doi: 10.1016/j.tcm.2014.10.012.

Bouska, I., Klir, P., and Markvartova, J. 2008. Arrhythmogenic right ventricular dysplasia/cardiomyopathy (ARVD/C) as a cause of sudden death. Soud Lek 
53(2): 18-20.

Brydon, L., Magid, K., and Steptoe, A. 2006. Platelets, coronary heart disease, and stress. Brain Behav. Immun. 20(2): 113-119. doi: 10.1016/j.bbi.2005.08.002.

Buxton, A.E., Ellison, K.E., Kirk, M.M., Frain, B., Koo, C., Gandhi, G., et al. 2003. Primary prevention of sudden cardiac death: trials in patients with coronary artery disease. J. Interv. Card. Electrophysiol. 9(2): 203-206.

Castellano, M., and Bohm, M. 1997. The cardiac beta-adrenoceptor-mediated signaling pathway and its alterations in hypertensive heart disease. Hypertension, 29(3): 715-722.

Coumbe, A., Perez-Martinez, A.L., Fegan, A.W., and Hill, I.R. 1997. Arrhythmogenic right ventricular dysplasia (ARVD): an overlooked and underdiagnosed condition? Med. Sci. Law, 37(3): 262-265.

Cruickshank, J.M. 2010. Beta blockers in hypertension. Lancet, 376(9739): 415; author reply 415-416. doi: 10.1016/S0140-6736(10)61217-2.

Czarny, M.J., and Resar, J.R. 2014. Diagnosis and management of valvular aortic stenosis. Clin. Med. Insights Cardiol. 8(Suppl 1): 15-24. doi: 10.4137/CMC.S15716.

Davis, J.A., Cecchin, F., Jones, T.K., and Portman, M.A. 2001. Major coronary artery anomalies in a pediatric population: incidence and clinical importance. J. Am. Coll. Cardiol. 37(2): 593-597.

Dhalla, N.S., Adameova, A., and Kaur, M. 2010. Role of catecholamine oxidation in sudden cardiac death. Fundam. Clin. Pharmacol. 24(5): 539-546. doi: 10.1111/j.1472-8206.2010.00836.x. 
Dhalla, N.S., Temsah, R.M., and Netticadan, T. 2000. Role of oxidative stress in cardiovascular diseases. J. Hypertens. 18(6): 655-673.

DiNicolantonio, J.J., Fares, H., Niazi, A.K., Chatterjee, S., D'Ascenzo, F., Cerrato, E., et al. 2015. beta-Blockers in hypertension, diabetes, heart failure and acute myocardial infarction: a review of the literature. Open Heart, 2(1): e000230. doi: 10.1136/openhrt-2014-000230.

Doval, H.C., Nul, D.R., Grancelli, H.O., Perrone, S.V., Bortman, G.R., and Curiel, R. Grupo de Estudio de la Sobrevida en la Insuficiencia Cardiaca en Argentina (GESICA).1994. Randomised trial of low-dose amiodarone in severe congestive heart failure. Lancet, 344(8921): 493-498.

Ferreira, M., Santos-Silva, P.R., de Abreu, L.C., Valenti, V.E., Crispim, V., Imaizumi, C., et al. 2010. Sudden cardiac death athletes: a systematic review. Sports Med. Arthrosc. Rehabil. Ther. Technol. 2: 19. doi: 10.1186/1758-2555-2-19.

Flett, A.S., Hayward, M.P., Ashworth, M.T., Hansen, M.S., Taylor, A.M., Elliott, P.M., et al. 2010. Equilibrium contrast cardiovascular magnetic resonance for the measurement of diffuse myocardial fibrosis: preliminary validation in humans. Circulation, 122(2): 138-144.

doi:10.1161/CIRCULATIONAHA.109.930636.

Francis, J., and Namboodiri, N. 2014. Update on ventricular tachyarrhythmias and related sudden cardiac death. Indian Pacing Electrophysiol. J. 14(6): 316319.

Franco, E., Dias, A., Teresa, D., and Hebert, K. 2014. EKG pattern of Brugada syndrome and sudden infant death syndrome--is it time to review the 
diagnostic criteria? Case report and review of literature. Ann. Noninvasive Electrocardiol. 19(2): 198-202. doi: 10.1111/anec.12086.

Freemantle, N., Cleland, J., Young, P., Mason, J., and Harrison, J. 1999. beta Blockade after myocardial infarction: systematic review and meta regression analysis. Brit. Med. J. 318(7200): 1730-1737.

Friedewald, V.E., Jr., and Spence, D.W. 1990. Sudden cardiac death associated with exercise: the risk-benefit issue. Am. J. Cardiol. 66(2): 183-188.

Gaither, N.S., Rogan, K.M., Stajduhar, K., Banks, A.K., Hull, R.W., Whitsitt, T., et al. 1991. Anomalous origin and course of coronary arteries in adults: identification and improved imaging utilizing transesophageal echocardiography. Am. Heart J. 122(1 Pt 1): 69-75.

Garcia-Gras, E., Lombardi, R., Giocondo, M.J., Willerson, J.T., Schneider, M.D., Khoury, D.S., et al. 2006. Suppression of canonical Wnt/beta-catenin signaling by nuclear plakoglobin recapitulates phenotype of arrhythmogenic right ventricular cardiomyopathy. J. Clin. Invest. 116(7): 2012-2021. doi: 10.1172/JCI27751.

Gersh, B.J., Maron, B.J., Bonow, R.O., Dearani, J.A., Fifer, M.A., Link, M.S., et al. 2011. 2011 ACCF/AHA guideline for the diagnosis and treatment of hypertrophic cardiomyopathy: executive summary: a report of the American College of Cardiology Foundation/American Heart Association Task Force on Practice Guidelines. J. Am. Coll. Cardiol. 58(25): 2703-2738. doi: 10.1016/j.jacc.2011.10.825.

Go, A.S., Yang, J., Gurwitz, J.H., Hsu, J., Lane, K., and Platt, R. 2008. Comparative with 
heart failure in clinical practice. Arch. Intern. Med. 168(22): 2415-2421. doi: 10.1001/archinternmed.2008.506.

Goldfarb, L.G., Park, K.Y., Cervenakova, L., Gorokhova, S., Lee, H.S., Vasconcelos, O., et al. 1998. Missense mutations in desmin associated with familial cardiac and skeletal myopathy. Nat. Genet. 19(4): 402-403. doi: 10.1038/1300.

Gonzalez-Melchor, L., Villarreal-Molina, T., Iturralde-Torres, P., and MedeirosDomingo, A. 2014. Sudden cardiac death in individuals with normal hearts: an update. Arch. Cardiol. Mex. 84(4): 293-304. doi: 10.1016/j.acmx.2014.04.002.

Gow, R. 2009. Preventing sudden cardiac death in the young: Is electrocardiogram screening the most effective means? Paediatr. Child Health, 14(3): 185-188.

Haft, J.I., Kranz, P.D., Albert, F.J., and Fani, K. 1972. Intravascular platelet aggregation in the heart induced by norepinephrine. Microscopic studies. Circulation, 46(4): 698-708.

Hammermeister, K.E., DeRouen, T.A., Murray, J.A., and Dodge, H.T. 1977. Effect of aortocoronary saphenous vein bypass grafting on death and sudden death. Comparison of nonrandomized medically and surgically treated cohorts with comparable coronary disease and left ventricular function. Am. J. Cardiol. 39(6): 925-934.

Hannan, E.L., Wu, C., Walford, G., Culliford, A.T., Gold, J.P., Smith, C.R., et al. 2008. Drug-eluting stents vs. coronary-artery bypass grafting in multivessel coronary disease. N. Engl. J. Med. 358(4): 331-341. doi: 10.1056/NEJMoa071804. 
Hauser, M. 2005. Congenital anomalies of the coronary arteries. Heart, 91(9): 12401245. doi: 10.1136/hrt.2004.057299.

Heitzer, T., Schlinzig, T., Krohn, K., Meinertz, T., and Munzel, T. 2001. Endothelial dysfunction, oxidative stress, and risk of cardiovascular events in patients with coronary artery disease. Circulation, 104(22): 2673-2678.

Iles, L., Pfluger, H., Phrommintikul, A., Cherayath, J., Aksit, P., Gupta, S.N., et al. 2008. Evaluation of diffuse myocardial fibrosis in heart failure with cardiac magnetic resonance contrast-enhanced T1 mapping. J. Am. Coll. Cardiol. 52(19): 1574-1580. doi: 10.1016/j.jacc.2008.06.049.

Iskandrian, A.S., Segal, B.L., Wasserman, L., Kimbiris, D., and Bemis, C.E. 1978. Sudden death in severe aortic stenosis following cardiac catheterization. Cathet. Cardiovasc. Diagn. 4(4): 419-425.

Kasper, E.K., Agema, W.R., Hutchins, G.M., Deckers, J.W., Hare, J.M., and Baughman, K.L. 1994. The causes of dilated cardiomyopathy: a clinicopathologic review of 673 consecutive patients. J. Am. Coll. Cardiol. 23(3): 586-590.

Kong, M.H., Fonarow, G.C., Peterson, E.D., Curtis, A.B., Hernandez, A.F., Sanders, G.D., et al. 2011. Systematic review of the incidence of sudden cardiac death in the United States. J. Am. Coll. Cardiol. 57(7): 794-801. doi: 10.1016/j.jacc.2010.09.064.

Krexi, L., Georgiou, R., Krexi, D., and Sheppard, M.N. 2015. Sudden cardiac death with stress and restraint: The association with sudden adult death syndrome, cardiomyopathy and coronary artery disease. Med. Sci. Law, doi: $10.1177 / 0025802414568483$. 
Kuhl, U., Pauschinger, M., Noutsias, M., Seeberg, B., Bock, T., Lassner, D., et al. 2005. High prevalence of viral genomes and multiple viral infections in the myocardium of adults with "idiopathic" left $\quad$ ventricular dysfunction. Circulation, 111(7): 887-893. doi: 10.1161/01.CIR.0000155616.07901.35.

Kulbertus, H.E. 1988. Ventricular arrhythmias, syncope and sudden death in aortic stenosis. Eur. Heart J. 9 Suppl E: 51-52.

Lange, R.A., and Hillis, L.D. 2003. Cardiology patient pages. Diagnostic cardiac catheterization. Circulation, 107(17): e111-113. doi:

10.1161/01.CIR.0000070982.94049.A2.

Lee, N.R., Park, J.H., and Rhee, K.S. 2008. Acquired long QT syndrome and sudden cardiac death due to secondary hemochromatosis with multitransfusions for severe aplastic anemia. Ann. Hematol. 87(11): 933-935. doi: 10.1007/s00277-008-0507-7.

Lerman, A., and Zeiher, A.M. 2005. Endothelial function: cardiac events. Circulation, 111(3): 363-368. doi: 10.1161/01.CIR.0000153339.27064.14.

Li, D., Liu, Y., Maruyama, M., Zhu, W., Chen, H., Zhang, W., et al. 2011a. Restrictive loss of plakoglobin in cardiomyocytes leads to arrhythmogenic cardiomyopathy. Hum. Mol. Genet. 20(23): 4582-4596. doi: 10.1093/hmg/ddr392.

Li, J., Swope, D., Raess, N., Cheng, L., Muller, E.J., and Radice, G.L. 2011b. Cardiac tissue-restricted deletion of plakoglobin results in progressive cardiomyopathy and activation of $\{$ beta\}-catenin signaling. Mol. Cell. Biol. 31(6): 1134-1144. doi: 10.1128/MCB.01025-10. 
Lopes, L.R., Zekavati, A., Syrris, P., Hubank, M., Giambartolomei, C., Dalageorgou, C., et al. 2013. Genetic complexity in hypertrophic cardiomyopathy revealed by high-throughput sequencing. J. Med. Genet. 50(4): 228-239. doi:

10.1136/jmedgenet-2012-101270.

Luk, A., Ahn, E., Soor, G.S., and Butany, J. 2009. Dilated cardiomyopathy: a review. J. Clin. Pathol. 62(3): 219-225. doi: 10.1136/jcp.2008.060731.

Marian, A.J., Salek, L., and Lutucuta, S. 2001. Molecular genetics and pathogenesis of hypertrophic cardiomyopathy. Minerva Med. 92(6): 435-451.

Maron, B.J. 1997. Risk profiles and cardiovascular preparticipation screening of competitive athletes. Cardiol. Clin. 15(3): 473-483.

Maron, B.J. 2002a. Cardiology patient pages. Hypertrophic cardiomyopathy. Circulation, 106(19): 2419-2421.

Maron, B.J. 2002b. Hypertrophic cardiomyopathy: a systematic review. J. Am. Med. Assoc. 287(10): 1308-1320.

Maron, B.J. 2002c. Risk stratification and prevention of sudden death in hypertrophic cardiomyopathy. Cardiol. Rev. 10(3): 173-181.

Maron, B.J., Leon, M.B., Swain, J.A., Cannon, R.O., 3rd, and Pelliccia, A. 1991. Prospective identification by two-dimensional echocardiography of anomalous origin of the left main coronary artery from the right sinus of Valsalva. Am. J. Cardiol. 68(1): 140-142.

Martino, T.A., Liu, P., and Sole, M.J. 1994. Viral infection and the pathogenesis of dilated cardiomyopathy. Circ. Res. 74(2): 182-188.

Menghetti, L., Basso, C., Nava, A., Angelini, A., and Thiene, G. 1996. Spin-echo nuclear 
magnetic resonance for tissue characterisation in arrhythmogenic right ventricular cardiomyopathy. Heart, 76(6): 467-470.

Mirowski, M., Reid, P.R., Mower, M.M., Watkins, L., Gott, V.L., Schauble, J.F., et al. 1980. Termination of malignant ventricular arrhythmias with an implanted automatic defibrillator in human beings. N. Engl. J. Med. 303(6): 322-324. doi: 10.1056/NEJM198008073030607.

Montgomery, J.V., Harris, K.M., Casey, S.A., Zenovich, A.G., and Maron, B.J. 2005. Relation of electrocardiographic patterns to phenotypic expression and clinical outcome in hypertrophic cardiomyopathy. Am. J. Cardiol. 96(2): 270275. doi: 10.1016/j.amjcard.2005.03.058.

Moon, J.C., Reed, E., Sheppard, M.N., Elkington, A.G., Ho, S.Y., Burke, M., et al. 2004. The histologic basis of late gadolinium enhancement cardiovascular magnetic resonance in hypertrophic cardiomyopathy. J. Am. Coll. Cardiol. 43(12): 2260-2264. doi: 10.1016/j.jacc.2004.03.035.

Morice, M.C., Serruys, P.W., Sousa, J.E., Fajadet, J., Ban Hayashi, E., Perin, M., Colombo, A., Schuler, G., Barragan, P., Guagliumi, G., Molnar, F., and Falotico, R. RAVEL Study Group. Randomized Study with the Sirolimus-Coated Bx Velocity Balloon-Expandable Stent in the Treatment of Patients with de Novo Native Coronary Artery Lesions. 2002. 2002. A randomized comparison of a sirolimus-eluting stent with a standard stent for coronary revascularization. N. Engl. J. Med. 346(23): 1773-1780. doi: 10.1056/NEJMoa012843.

Morita, H., Rehm, H.L., Menesses, A., McDonough, B., Roberts, A.E., Kucherlapati, R., et al. 2008. Shared genetic causes of cardiac hypertrophy in children and 
adults. N. Engl. J. Med. 358(18): 1899- $\quad$ 1908. doi:

10.1056/NEJMoa075463.

Moses, J.W., Leon, M.B., Popma, J.J., Fitzgerald, P.J., Holmes, D.R., O'Shaughnessy, C., Caputo, R.P., Kereiakes, D.J., Williams, D.O., Teirstein, P.S., Jaeger, J.L., Kuntz, R.E., for the SIRIUS Investigators. 2003. Sirolimus-eluting stents versus standard stents in patients with stenosis in a native coronary artery. N. Engl. J. Med. 349(14): 1315-1323. doi: 10.1056/NEJMoa035071.

Murray, B. 2012. Arrhythmogenic right ventricular dysplasia/cardiomyopathy (ARVD/C): a review of molecular and clinical literature. J. Genet. Couns. 21(4): 494-504. doi: 10.1007/s10897-012-9497-7.

Oldfors, A., Eriksson, B.O., Kyllerman, M., Martinsson, T., and Wahlstrom, J. 1994. Dilated cardiomyopathy and the dystrophin gene: an illustrated review. Br. Heart J. 72(4): 344-348.

Postema, P.G., and Wilde, A.A. 2008. Do patients with long QT syndrome remain at risk for sudden cardiac death after 40 years of age? Nat. Clin. Pract. Cardiovasc. Med. 5(10): 602-603. doi: 10.1038/ncpcardio1305.

Richardson, P., McKenna, W., Bristow, M., Maisch, B., Mautner, B., O'Connell, J., et al. 1996. Report of the 1995 World Health Organization/International Society and Federation of Cardiology Task Force on the Definition and Classification of cardiomyopathies. Circulation, 93(5): 841-842.

Roden, D.M. 2008. Clinical practice. Long-QT syndrome. N. Engl. J. Med. 358(2): 169176. doi: 10.1056/NEJMcp0706513.

Rollins, G. 2001. Low daily aspirin doses reduce risk of blood clots as effectively as 
higher doses. Rep. Med. Guidel Outcomes Res. 12(4): 5-7.

Rollins, G. 2002. Aspirin therapy now recommended for people at risk for heart disease. Rep. Med. Guidel Outcomes Res. 13(3): 1-2, 5.

Rona, G., Boutet, M., Huttner, I., and Peters, H. 1973. Pathogenesis of isoproterenolinduced myocardial alterations: functional and morphological correlates. Recent Adv. Stud. Cardiac Struct. Metab. 3: 507-525.

Ross, J., Jr. 2002. Dilated cardiomyopathy: concepts derived from gene deficient and transgenic animal models. Circ. J. 66(3): 219-224.

Ruiz Ruiz, F.J., Gonzalez Cortijo, J., Zalba Etayo, B., Leon Cinto, C., and Sanchez Miret, J.I. 2003. Asymptomatic aortic valve stenosis and sudden death. An. Med. Interna. 20(10): 529-531.

Saenen, J.B., and Vrints, C.J. 2008. Molecular aspects of the congenital and acquired Long QT Syndrome: clinical implications. J. Mol. Cell Cardiol. 44(4): 633-646. doi: 10.1016/j.yjmcc.2008.01.006.

Sara, J.D., Eleid, M.F., Gulati, R., and Holmes, D.R., Jr. 2014. Sudden cardiac death from the perspective of coronary artery disease. Mayo Clin. Proc. 89(12): 16851698. doi: 10.1016/j.mayocp.2014.08.022.

Sequeira, V., Nijenkamp, L.L., Regan, J.A., and van der Velden, J. 2014. The physiological role of cardiac cytoskeleton and its alterations in heart failure. Biochim. Biophys. Acta, 1838(2): 700-722. doi: 10.1016/j.bbamem.2013.07.011.

Shimizu, W., and Shimomura, K. 1991. Arrhythmogenic right ventricular dysplasia (ARVD). Nihon Rinsho 49(11): 2630-2634. 
Singh, S.N., Fletcher, R.D., Fisher, S.G., Singh, B.N., Lewis, H.D., Deedwania, P.C., et al. 1995. Amiodarone in patients with congestive heart failure and asymptomatic ventricular arrhythmia. Survival Trial of Antiarrhythmic Therapy in Congestive Heart Failure. N. Engl. J. Med. 333(2): 77-82. doi: 10.1056/NEJM199507133330201.

Spieker, L.E., Hurlimann, D., Ruschitzka, F., Corti, R., Enseleit, F., Shaw, S., et al. 2002. Mental stress induces prolonged endothelial dysfunction via endothelin-A receptors. Circulation, 105(24): 2817-2820.

Spirito, P., and Maron, B.J. 1990. Relation between extent of left ventricular hypertrophy and occurrence of sudden cardiac death in hypertrophic cardiomyopathy. J. Am. Coll. Cardiol. 15(7): 1521-1526.

Spirito, P., Maron, B.J., Chiarella, F., Bellotti, P., Tramarin, R., Pozzoli, M., et al. 1985. Diastolic abnormalities in patients with hypertrophic cardiomyopathy: relation to magnitude of left ventricular hypertrophy. Circulation, 72(2): $310-316$.

Stahley, S.N., and Kowalczyk, A.P. 2015. Desmosomes in acquired disease. Cell Tissue Res. 360(3): 439-456. doi: 10.1007/s00441-015-2155-2.

Steinfath, M., Danielsen, W., von der Leyen, H., Mende, U., Meyer, W., Neumann, J., et al. 1992. Reduced alpha 1- and beta 2-adrenoceptor-mediated positive inotropic effects in human end-stage heart failure. Br. J. Pharmacol. 105(2): 463-469.

Stork, S., Hense, H.W., Zentgraf, C., Uebelacker, I., Jahns, R., Ertl, G., and Angermann, C.E. 2008. Pharmacotherapy according to treatment guidelines is associated 
with lower mortality in a community-based sample of patients with chronic heart failure: a prospective cohort study. Eur. J. Heart Fail. 10(12): 12361245. doi: 10.1016/j.ejheart.2008.09.008.

Tabib, A., Loire, R., Chalabreysse, L., Meyronnet, D., Miras, A., Malicier, D., et al. 2003. Circumstances of death and gross and microscopic observations in a series of 200 cases of sudden death associated with arrhythmogenic right ventricular cardiomyopathy and/or dysplasia. Circulation, 108(24): 3000-3005. doi: 10.1161/01.CIR.0000108396.65446.21.

Tandri, H., Macedo, R., Calkins, H., Marcus, F., Cannom, D., Scheinman, M., Daubert, J., Estes, M., 3rd, Wilber, D., Talajic, M., Duff, H., Krahn, A., Sweeney, M., Garan, H., Bluemke, D.A. Multidisciplinary Study of Right Ventricular Dysplasia Investigators. 2008. Role of magnetic resonance imaging in arrhythmogenic right ventricular dysplasia: insights from the North American arrhythmogenic right ventricular dysplasia (ARVD/C) study. Am. Heart J. 155(1): 147-153. doi: 10.1016/j.ahj.2007.08.011.

Thiene, G. 2014. Sudden cardiac death and cardiovascular pathology: from anatomic theater to double helix. Am. J. Cardiol. 114(12): 1930-1936. doi: 10.1016/j.amjcard.2014.09.037.

Thorsen, P.J., Berg, A., Hoff, P.I., and Greve, G. 2006. Risk factors for sudden cardiac death related to the long QT syndrome. Tidsskr Nor Laegeforen 126(19): 2515-2519.

Vincent, G.M. 2005. The Long QT and Brugada syndromes: causes of unexpected syncope and sudden cardiac death in children and young adults. Semin. 
Pediatr. Neurol. 12(1): 15-24.

Wagner, A., Mahrholdt, H., Holly, T.A., Elliott, M.D., Regenfus, M., Parker, M., et al. 2003. Contrast-enhanced MRI and routine single photon emission computed tomography (SPECT) perfusion imaging for detection of subendocardial myocardial infarcts: an imaging study. Lancet, 361(9355): 374-379. doi: 10.1016/S0140-6736(03)12389-6.

Wolfe, B.A., and Corwin, E.J. 2005. ARVD: a silent killer. Nurse Pract. 30(5): 16-18, 23-17; quiz 27-19.

Yajima, T., and Knowlton, K.U. 2009. Viral myocarditis: from the perspective of the virus. Circulation, 119(19): 2615-2624. doi:

10.1161/CIRCULATIONAHA.108.766022.

Yamanaka, O., and Hobbs, R.E. 1990. Coronary artery anomalies in 126,595 patients undergoing coronary arteriography. Cathet. Cardiovasc. Diagn. 21(1): 28-40.

Zhang, H., Facemire, C.S., Banes, A.J., and Faber, J.E. 2002. Different alphaadrenoceptors mediate migration of vascular smooth muscle cells and adventitial fibroblasts in vitro. Am. J. Physiol. 282(6):H2364-2370. doi: 10.1152/ajpheart.00858.2001.

Zhou, Y.H., Wei, X., Lu, J., Ye, X.F., Wu, M.J., Xu, J.F., et al. 2012. Effects of combined aspirin and clopidogrel therapy on cardiovascular outcomes: a systematic review and meta-analysis. PLoS One, 7(2): e31642. doi:

10.1371/journal.pone.0031642.

Zolk, O., Caroni, P., and Bohm, M. 2000. Decreased expression of the cardiac LIM domain protein MLP in chronic human heart failure. Circulation, 101(23): 
2674-2677.

\section{Figure Legends}

Figure 1: Etiologies that increase the risk of sudden cardiac death in different diseases.

Figure 2: Various medical therapies and interventions for the prevention of sudden cardiac death associated with different diseases. 


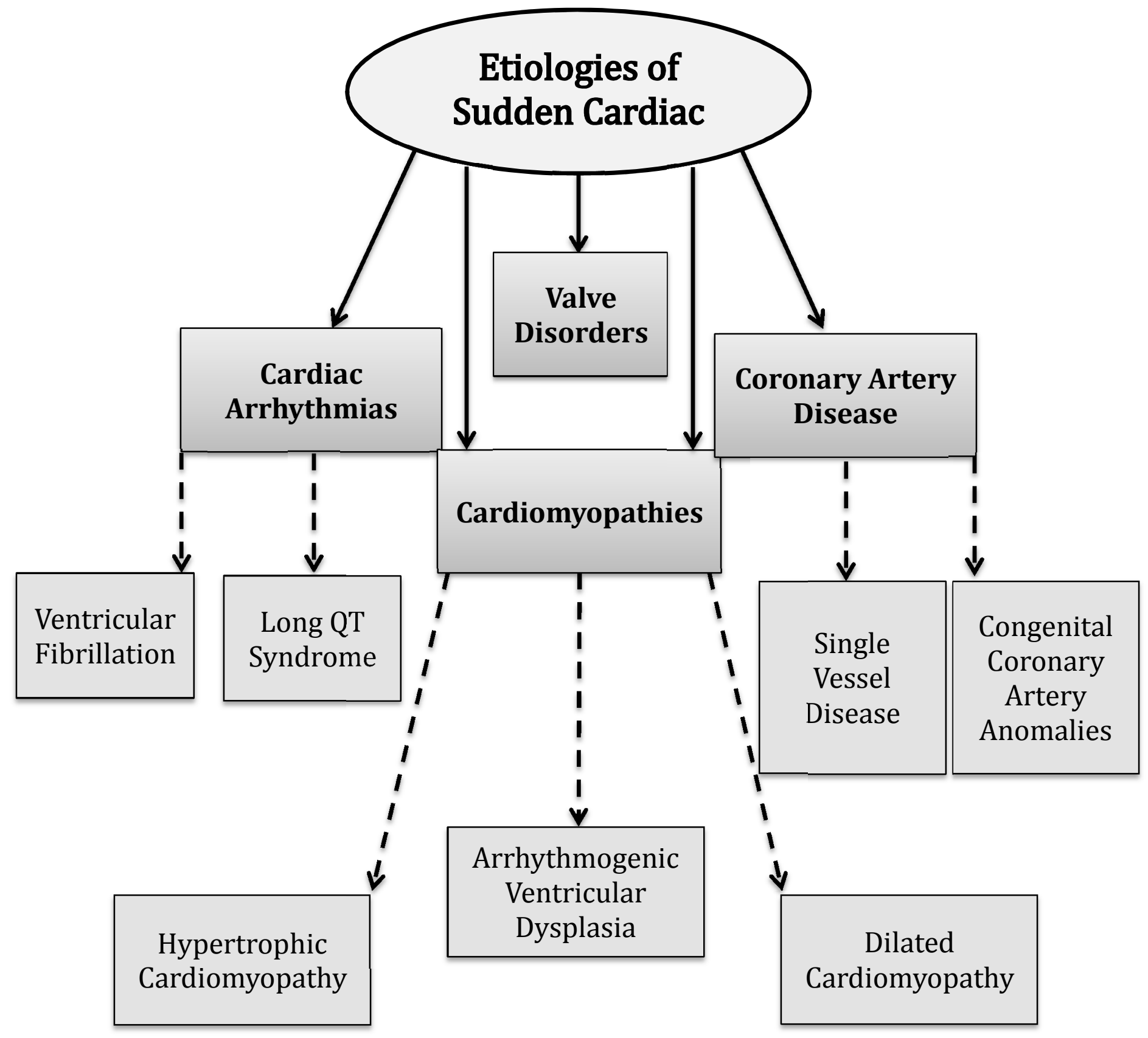

Figure 1

(Goyal et al) 


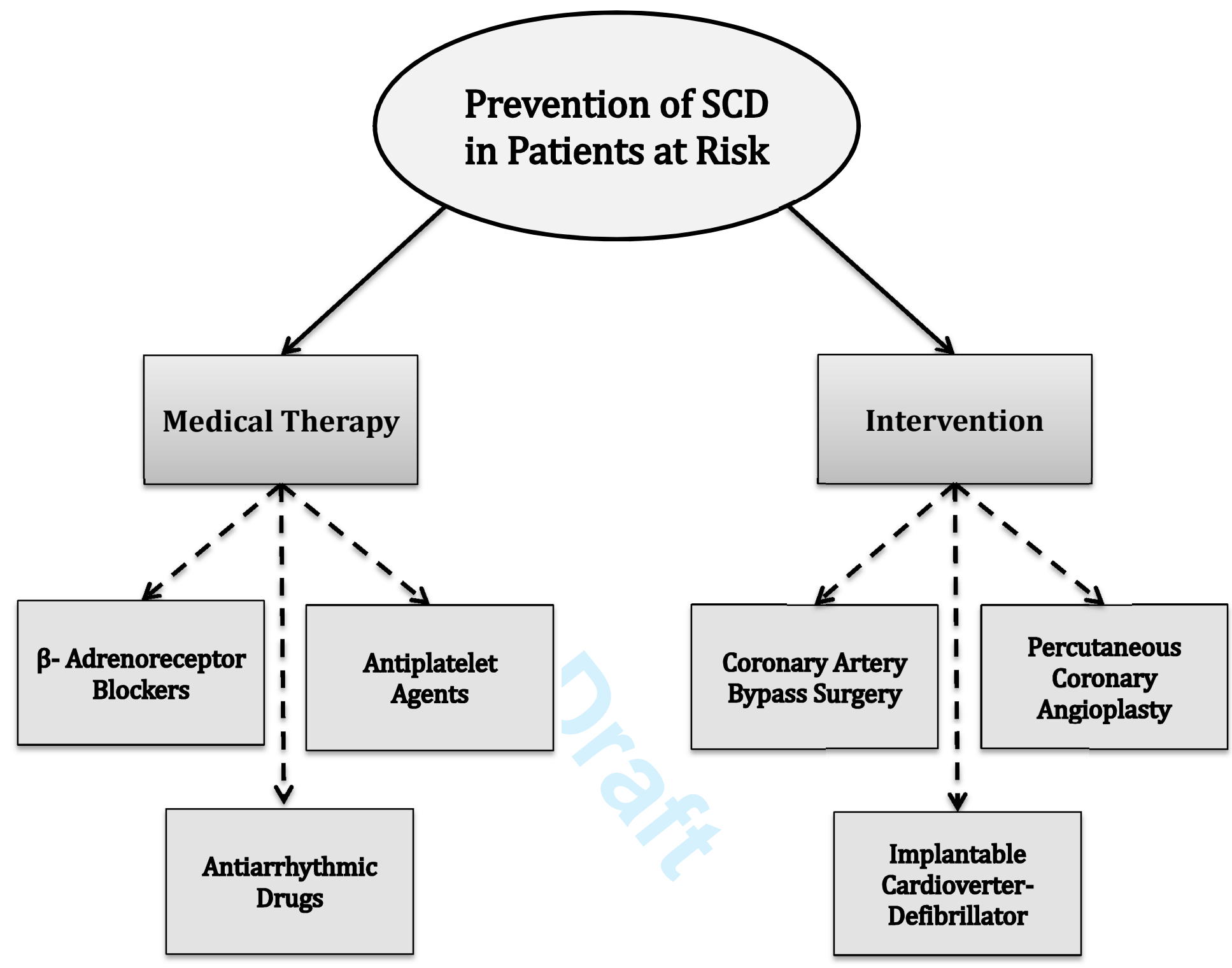

Figure 2

(Goyal et al) 